\title{
In Situ Synthesis and Deposition of Gold Nanoparticles with Different Morphologies on Glass and ITO Substrate by Ultrasonic Spray Pyrolysis
}

\author{
María de la Garza, Israel López, and Idalia Gómez \\ Universidad Autónoma de Nuevo León (UANL), Facultad de Ciencias Químicas, Avenida Universidad, Ciudad Universitaria, \\ 66451 San Nicolás de los Garza, NL, Mexico
}

Correspondence should be addressed to Idalia Gómez; idaliagomezmx@yahoo.com.mx

Received 17 May 2013; Accepted 28 August 2013

Academic Editor: Mohd Sapuan Salit

Copyright (C) 2013 María de la Garza et al. This is an open access article distributed under the Creative Commons Attribution License, which permits unrestricted use, distribution, and reproduction in any medium, provided the original work is properly cited.

Gold nanoparticles were synthesized and deposited in situ by ultrasonic spray pyrolysis on glass and indium tin oxide (ITO) substrates. This technique led to the formation of gold nanoparticles with different morphologies without the use of any capping agent. The gold nanoparticles deposited on glass substrate were obtained as nanospheres with an average particle size of $30 \mathrm{~nm}$ with some agglomerates; however, the nanoparticles deposited on ITO substrate were obtained with different morphologies, such as triangular nanoprisms, nanorods, nanocubes, and nanorhombus, with particle sizes between 40 and $100 \mathrm{~nm}$. The ITO substrate influenced the morphology of the gold nanoparticles obtained due to changes in the deposition temperature, which also change the crystalline structure of the ITO film on the substrate.

\section{Introduction}

In recent years, metallic nanoparticles have generated a great interest in different fields due to their unique properties, which made them suitable for applications such as chemical imaging [1], solar cells [2], biomaterials [3], adsorption of organic molecules [4], surface-enhanced Raman scattering [5], and sensors and biosensors [6-9]. Of particular interest are the optical properties, given by the surface plasmon resonance (SPR), which is the collective oscillation of the electrons within the conduction band in response to the electrical field of the incident light. The SPR depends on the size, shape, and geometry of the particles; these factors affect the sensibility of the nanoparticles when they are being used as sensors [9].

There are several methods reported for depositing gold nanoparticles on different substrates, such as aerosol techniques, which are simple and low cost methods and have great versatility, high deposition rates, and narrow particle size distributions [10]. Ultrasonic spray pyrolysis is an aerosol technique widely used for the synthesis of different materials, specially metals and metal oxides, and it can lead to the formation of different morphologies such as nanowires, nanorods, and nanotubes, depending on the conditions used in the deposition [11-15].

Preparation of gold nanostructures with different morphologies on ITO (indium-doped tin oxide) substrates has been performed with seed-mediated growth techniques using capping agents such as poly(vinylpyrrolidone) (PVP) and cetyltrimethylammonium bromide (CETAB) acting as morphology directors due to their molecular structure, which are absorbed on certain planes of the growing gold nanoparticles and can lead to the formation of nanoprisms, nanorods, nanocubes, and so forth $[16,17]$. To the best of our knowledge, the formation of gold nanoparticles with different morphologies on ITO substrates by aerosol techniques without any capping agent has never been reported.

In this work, ultrasonic spray pyrolysis was used for the in situ synthesis and deposition of gold nanoparticles on glass and ITO substrates, without the use of any capping agent. The influence of the substrate on the morphology of the gold nanoparticles was observed. 


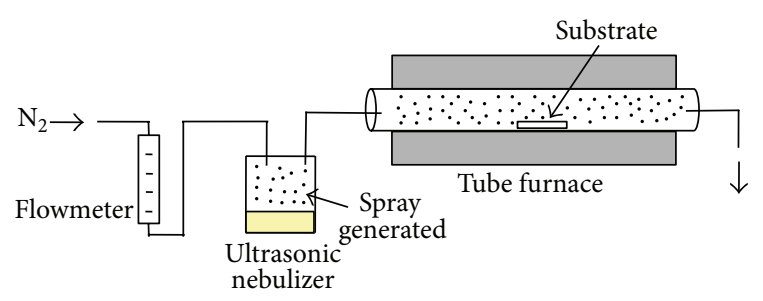

Figure 1: Diagram of the ultrasonic spray pyrolysis system.

\section{Materials and Methods}

Glass (Corning microscope slides) and ITO (Sigma-Aldrich, surface resistivity: 15-25 $\Omega /$ sq) substrates were cleaned ultrasonically for $5 \mathrm{~min}$ using acetone, ethanol, and water. For the in situ synthesis and deposition, a solution of $\mathrm{HAuCl}_{4}$ $0.25 \mathrm{mM}$ was used as precursor for the generation of gold nanoparticles, and this solution was placed in a medical ultrasonic nebulizer using a frequency of $1.7 \mathrm{MHz}$. The generated spray was passed through a quartz tube using nitrogen as carrier gas with a flow rate of $2 \mathrm{~L} / \mathrm{min}$. The substrates were placed inside the quartz tube contained within a tube furnace heated to $300^{\circ} \mathrm{C}$. A diagram of the system used in this work is shown in Figure 1. The synthesis of gold nanoparticles took place inside the tube furnace, according to (1), which occurs above $175^{\circ} \mathrm{C}[18,19]$ as

$$
\mathrm{HAuCl}_{4} \longrightarrow \mathrm{Au}_{(\mathrm{s})}+\mathrm{HCl}_{(\mathrm{g})}+\frac{3}{2} \mathrm{Cl}_{2(\mathrm{~g})}
$$

The deposition of gold nanoparticles on ITO substrates was also carried out using two flow rates of the carrier gas (2 and $3 \mathrm{~L} / \mathrm{min}$ ) and three temperatures $\left(200,300\right.$, and $\left.400^{\circ} \mathrm{C}\right)$, with the finality to observe the influence of these conditions on the different morphologies obtained.

The optical properties of the gold nanoparticles were determined by UV-Vis spectroscopy with a Perkin Elmer Lambda 12 spectrophotometer. The morphology of gold nanoparticles deposited on the substrates was determined by field-emission scanning electron microscopy (FE-SEM) using a JEOL JSM-6701F microscope and by atomic force microscope (AFM) with a AA3000 Scanning Probe Microscope (Angstrom Advanced Inc.). An energy dispersive Xray analysis (EDX) was performed on the gold nanoparticles deposited on ITO substrate to confirm its presence.

\section{Results and Discussion}

In Figure 2, the FE-SEM and 3D AFM images for the synthesis and deposition of gold nanoparticles on glass substrates at $300^{\circ} \mathrm{C}$ and $2 \mathrm{~L} / \mathrm{min}$ are shown. The deposition was uniform on the surfaces of the substrate and the morphology obtained was nanospheres, which showed an average particle size of $30 \mathrm{~nm}$, with some agglomerates between 100 and $150 \mathrm{~nm}$ being obtained. These agglomerates are obtained because at temperatures higher than $250^{\circ} \mathrm{C}$ the gold nanoparticles begin to coalesce, carried out by surface atom diffusion to minimize the surface area, and larger nanoparticles are observed [20].
Figure 3 shows the FE-SEM images for the deposition on ITO substrate at $300^{\circ} \mathrm{C}$ and $2 \mathrm{~L} / \mathrm{min}$; the formation of gold nanoparticles with different morphologies such as nanospheres, triangular nanoprisms, nanorods, nanocubes, and nanorhombus was observed without formation of any agglomerate, unlike the deposition on glass substrates which only led to the formation of nanospheres. The substrate plays an important role in the growth of gold nanoparticles with different morphologies, and ITO films on the substrate act in some degree as morphology director; it has been reported that this material can lead to the formation of gold nanoparticles with multiple shapes by using a seed-mediated growth method that is helped by the applied potential to the ITO substrate [21]. In this work, the temperature applied to the deposition modifies the ITO surface and the formation of nanoparticles with different morphologies is obtained, as will be discussed later. We propose that the formation of the gold nanoparticles starts by nucleation of gold nanoseeds on the ITO surface and then continues with their growth, and this is carried out at low driving forces due to the obtention of two-dimensional nanostructures [22]. EDX pattern of the gold nanoparticles deposited on the ITO substrate is shown in Figure $3(\mathrm{~d})$, and the representative gold peaks are observed, which confirms the formation of gold nanoparticles by ultrasonic spray pyrolysis proposed in this work. Other peaks for In, Sn, O, and Ca are also observed due to the substrate.

The yield of the different morphologies was calculated from the FE-SEM images shown in Figure 3. The approximately yield percentage of each morphology was $36 \%$ for nanorhombus, $20 \%$ for triangular nanoprisms, $17 \%$ for nanorods, and $15 \%$ for nanocubes. The main morphologies obtained were triangular nanoprisms and nanorhombus. The triangular nanoprisms have edges of around $58 \mathrm{~nm}$, the length of the nanorods is below $100 \mathrm{~nm}$, and the particle size of the nanorhombus and nanocubes is between 45 and $60 \mathrm{~nm}$ and 30 and $45 \mathrm{~nm}$, respectively.

The UV-Vis spectra for the gold nanoparticles on the glass and ITO substrate are shown in Figure 4. The surface plasmon resonance (SPR) peak for the gold nanoparticles on glass was observed at $539 \mathrm{~nm}$, and for the nanoparticles on ITO a less defined peak was obtained at $520 \mathrm{~nm}$; this peak form is due to the light scattering caused by the ITO film and the peak position is because there is no agglomeration in the gold nanoparticles deposited on ITO and the interactions between the gold nanoparticles and the substrates are different. It is worth mentioning that the UVVis spectrum for the gold nanoparticles on ITO substrate only shows the SPR peak corresponding to in-plane dipolar resonance and none of the other resonances observed in gold nanoparticles with different shapes, because the orientation of the gold nanoparticles on the substrate is restricted and only the $\{111\}$ plane is exposed to the incident light; therefore, the other resonances cannot be stimulated.

Figure 5 shows FE-SEM images of the gold nanoparticles deposited on ITO substrates at the different conditions. For 2 and $3 \mathrm{~L} / \mathrm{min}$, gold nanoparticles were obtained with different morphologies, such as triangular nanoprisms, nanorods, nanocubes, and nanorhombus (as can be seen in FE-SEM images of Figure 3 at higher magnification), and some 


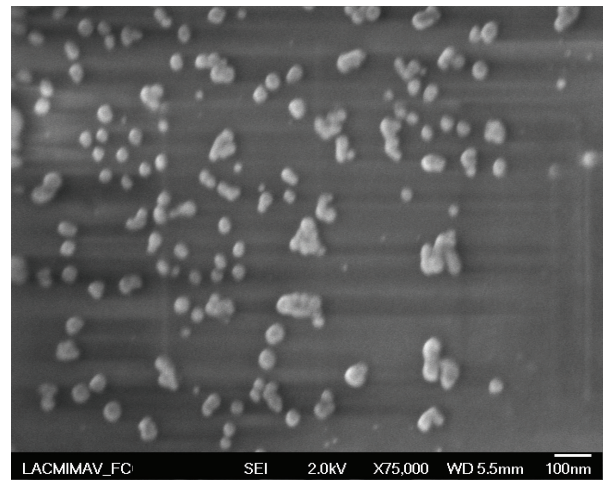

(a)

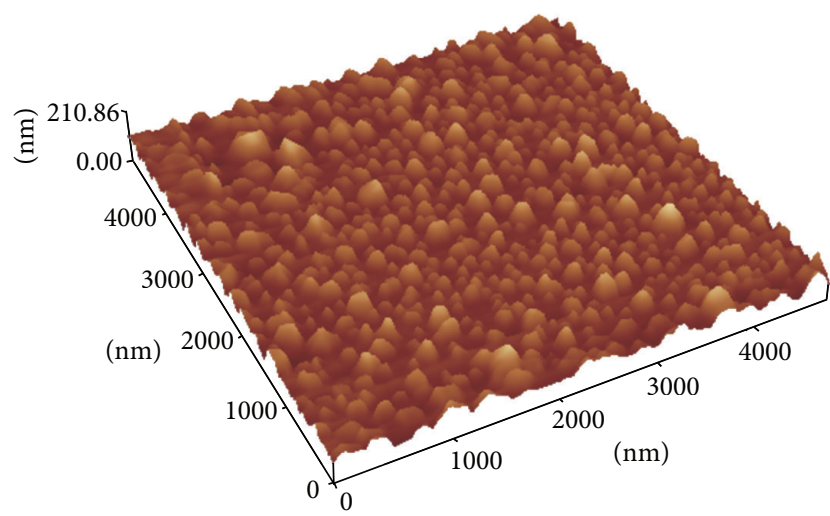

(b)

FIgURE 2: (a) FE-SEM and (b) 3D AFM images of gold nanoparticles deposited on a glass substrate with a flow rate of $2 \mathrm{~L} / \mathrm{min}$ at $300^{\circ} \mathrm{C}$.

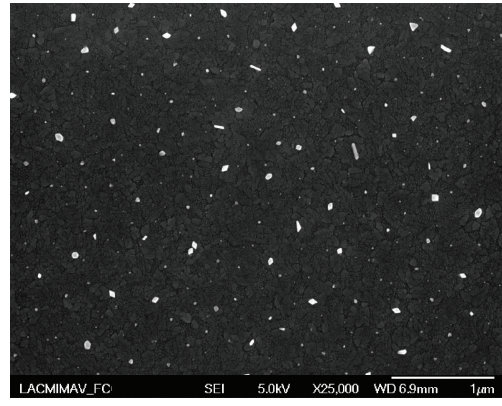

(a)

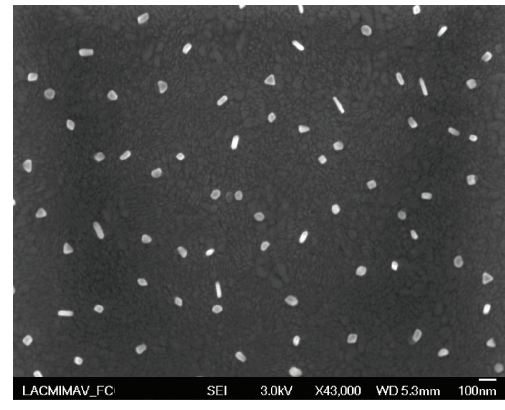

(b)

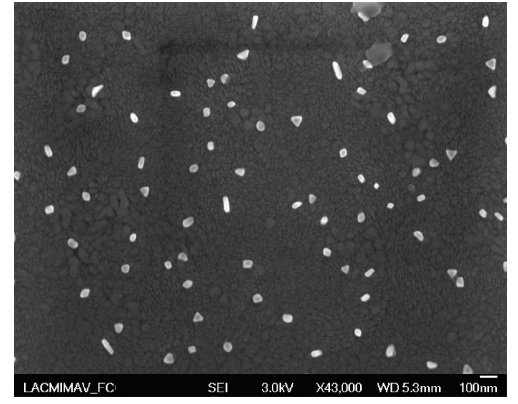

(c)

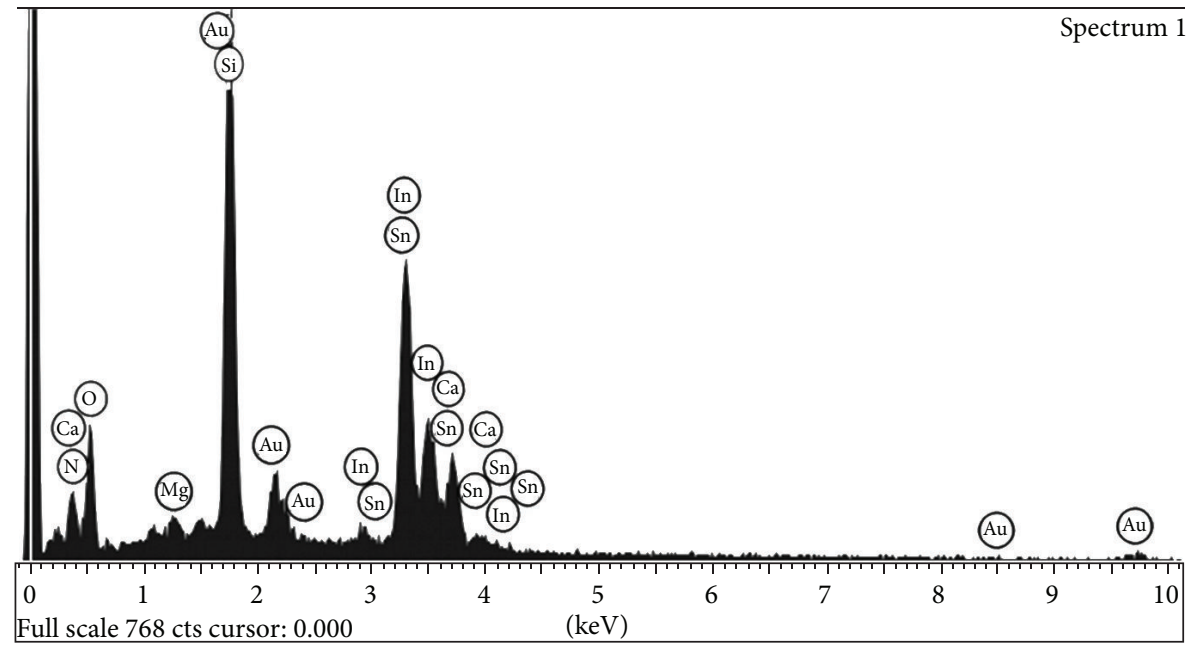

(d)

FiguRE 3: ((a), (b), and (c)) FE-SEM images of multishape gold nanoparticles deposited on an ITO substrate with a flow rate of $2 \mathrm{~L} / \mathrm{min}$ at $300^{\circ} \mathrm{C}$ and (d) EDX pattern of gold nanoparticles deposited on ITO substrates.

nanohexagons and nanopentagons are also observed but in less proportion. For a flow rate of $3 \mathrm{~L} / \mathrm{min}$ the number of nanoparticles deposited is higher than $2 \mathrm{~L} / \mathrm{min}$, because the spray concentration in the tube furnace is higher when the flow rate increases; therefore, more particles that can be deposited are present, but in both cases the formation of nanoparticles with different morphology is obtained. The temperature has a major effect on the nanoparticles obtained; for gold nanoparticles deposited at higher temperature, the number of particles is larger and the particles are smaller than those obtained at lower temperature. However, the temperature and flow rate do not have a major effect on the different morphologies obtained, and these two conditions only affect the number and size of the deposited particles.

Changes in the ITO structure such as the temperature increase also have influence on the morphology of the gold 


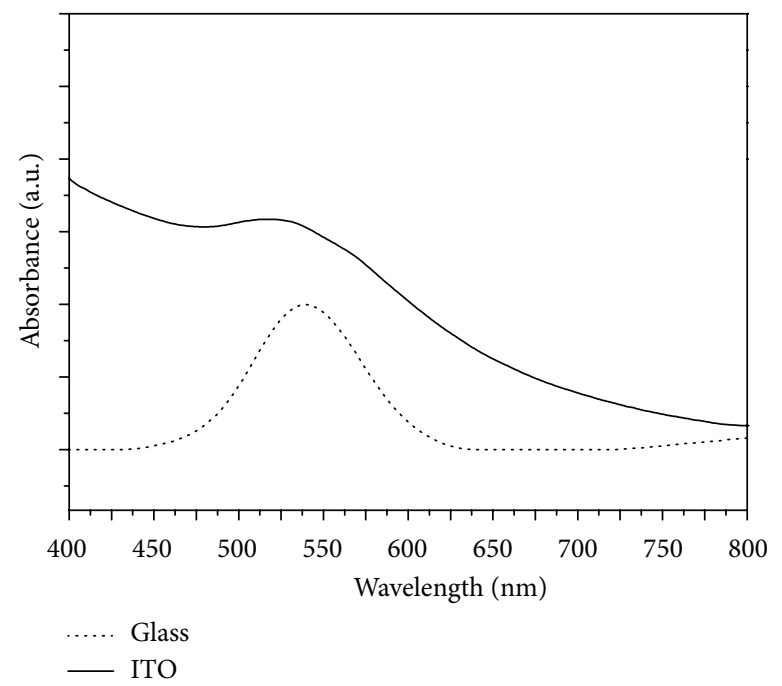

FIGURE 4: UV-Vis spectra of gold nanoparticles deposited on glass and ITO substrate with a flow rate of $2 \mathrm{~L} / \mathrm{min}$ at $300^{\circ} \mathrm{C}$.

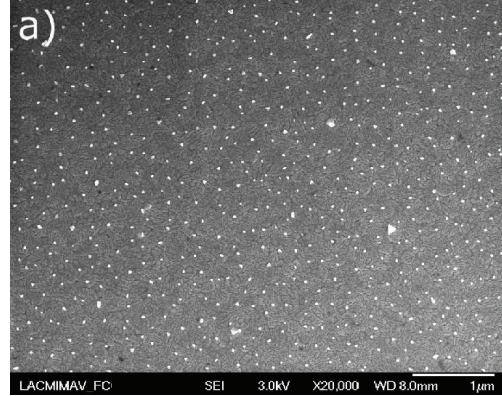

(a)

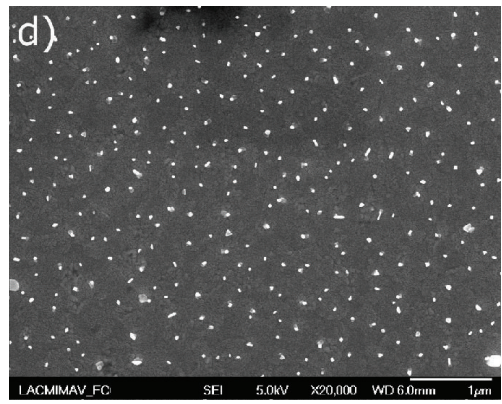

(d)

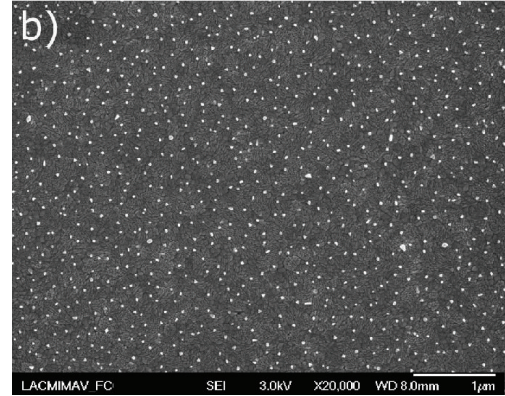

(b)

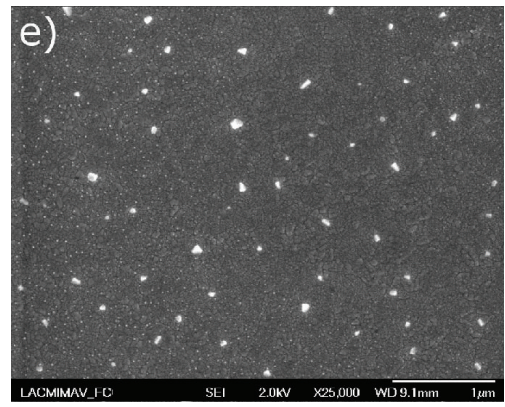

(e)

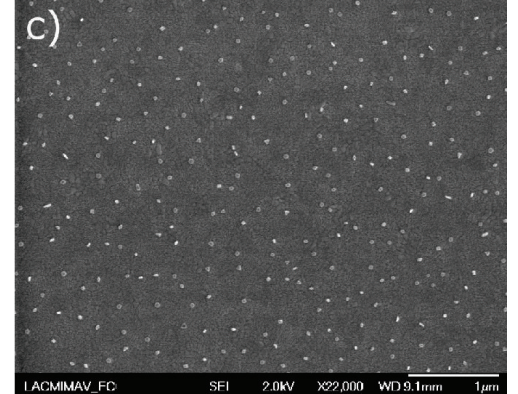

(c)

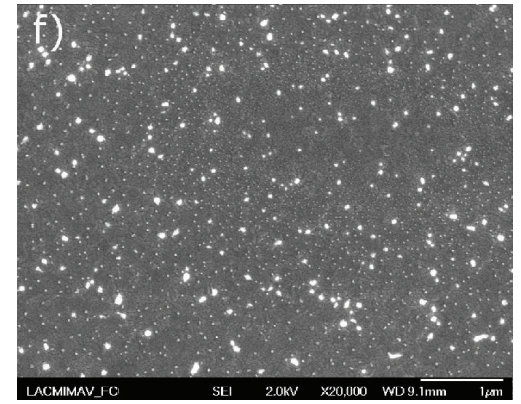

(f)

FIGURE 5: FE-SEM images of gold nanoparticles deposited on ITO substrates with a flow rate of $2 \mathrm{~L} / \mathrm{min}$ at (a) 400 , (c), 300 and (e) $200^{\circ} \mathrm{C}$ and $3 \mathrm{~L} / \mathrm{min}$ at (b) $400,(\mathrm{~d}), 300$ and (f) $200^{\circ} \mathrm{C}$.

nanoparticles; the ITO film is in an amorphous phase at lower temperatures with defects in the structure and a nonstoichiometric composition; as the temperature increases, the crystallization occurs at temperature higher than $300^{\circ} \mathrm{C}$ with the formation of $\mathrm{In}_{2} \mathrm{O}_{3}$ in cubic phase, the defects decrease, and the roughness increases [23, 24]. The results obtained with the deposition at different temperatures may indicate that the nucleation and growth process are dominant at high and low temperatures, respectively, which is due to the relatively higher thermodynamic level of the substrate at higher temperatures and to differences in the crystalline structure of the ITO film at different temperatures. Unlike the deposition of gold nanoparticles on glass substrate, where there is no stabilization due to presence of other phases on the substrate. Also the ITO surface leads to a growth on the side facets rather than the flat facets, and also it helps to stabilize the $\{111\}$ plane of the gold nanoparticles. This is the reason why the main morphologies obtained are nanorhombus and triangular nanoprisms.

\section{Conclusions}

The in situ synthesis and deposition of gold nanoparticles with different morphologies on glass and ITO substrates were 
achieved by ultrasonic spray pyrolysis without the use of any capping agent. The nanoparticles morphologies obtained on ITO substrate were triangular nanoprisms, nanorods, nanocubes, and nanorhombus. However, by using glass as a substrate, only gold nanospheres were formed, which indicates that the ITO substrate plays an important role in the morphology of the deposited nanoparticles. The nucleation process is dominant at higher temperatures due to relatively higher thermodynamic level and to changes in the crystalline structure of the ITO film on the substrate.

\section{Acknowledgment}

The authors would like to thank the Consejo Nacional de Ciencia y Tecnología (CONACYT) for supporting this project under Grant CB 2010157745.

\section{References}

[1] R. B. P. Elmes, K. N. Orange, S. M. Cloonan, D. C. Williams, and T. Gunnlaugsson, "Luminescent ruthenium(II) polypyridyl functionalized gold nanoparticles; their DNA binding abilities and application as cellular imaging agents," Journal of the American Chemical Society, vol. 133, no. 40, pp. 15862-15865, 2011.

[2] I.-K. Ding, J. Zhu, W. Cai et al., "Plasmonic back reflectors: plasmonic dye-sensitized solar cells," Advanced Energy Materials, vol. 1, no. 1, pp. 52-57, 2011.

[3] H. Hermawan, D. Dubé, and D. Mantovani, "Degradable metallic biomaterials for cardiovascular applications," in Metals for Biomedical Devices, M. Niinomi, Ed., chapter 16, pp. 379404, Woodhead Publishing, Cambridge, UK, 2010.

[4] S. L. Tait, Z. Dohnálek, C. T. Campbell, and B. D. Kay, "Methane adsorption and dissociation and oxygen adsorption and reaction with $\mathrm{CO}$ on $\mathrm{Pd}$ nanoparticles on $\mathrm{MgO}\left(\begin{array}{lll}1 & 0 & 0\end{array}\right)$ and on Pd(1 1 1)," Surface Science, vol. 591, no. 1-3, pp. 90-107, 2005.

[5] Q. Su, X. Ma, J. Dong, C. Jiang, and W. Qian, "A reproducible SERS substrate based on electrostatically assisted aptes-functionalized surface-assembly of gold nanostars," ACS Applied Materials and Interfaces, vol. 3, no. 6, pp. 1873-1879, 2011.

[6] B. Sepúlveda, P. C. Angelomé, L. M. Lechuga, and L. M. LizMarzán, “LSPR-based nanobiosensors," Nano Today, vol. 4, no. 3, pp. 244-251, 2009.

[7] K. M. Mayer and J. H. Hafner, "Localized surface plasmon resonance sensors," Chemical Reviews, vol. 111, no. 6, pp. 38283857, 2011.

[8] K. Saha, S. S. Agasti, C. Kim, X. Li, and V. M. Rotello, "Gold nanoparticles in chemical and biological sensing," Chemical Reviews, vol. 112, no. 5, pp. 2739-2779, 2012.

[9] J. Z. Zhang, Optical Properties and Spectroscopy of Nanomaterials, World Scientific Publishing Company, Singapore, 1st edition, 2009.

[10] T. Kodas and M. Hampden-Smith, Aerosol Processing of Materials, Wiley-VCH, New York, NY, USA, 1st edition, 1999.

[11] M. T. Htay, Y. Hashimoto, N. Momose, and K. Ito, "Positionselective growth of $\mathrm{ZnO}$ nanowires by ultrasonic spray pyrolysis," Journal of Crystal Growth, vol. 311, no. 20, pp. 4499-4504, 2009.

[12] M. A. Montero, M. R. Gennero de Chialvo, and A. C. Chialvo, "Preparation of gold nanoparticles supported on glassy carbon by direct spray pyrolysis," Journal of Materials Chemistry, vol. 19, no. 20, pp. 3276-3280, 2009.

[13] U. Alver, T. Kılınç, E. Bacaksiz, and S. Nezir, "Temperature dependence of $\mathrm{ZnO}$ rods produced by ultrasonic spray pyrolysis method," Materials Chemistry and Physics, vol. 106, no. 2-3, pp. 227-230, 2007.

[14] H. Zhang and M. T. Swihart, "Synthesis of tellurium dioxide nanoparticles by spray pyrolysis," Chemistry of Materials, vol. 19, no. 6, pp. 1290-1301, 2007.

[15] S. E. Skrabalak and K. S. Suslick, "Porous $\mathrm{MoS}_{2}$ synthesized by ultrasonic spray pyrolysis," Journal of the American Chemical Society, vol. 127, no. 28, pp. 9990-9991, 2005.

[16] V. G. Praig, G. Piret, M. Manesse, X. Castel, R. Boukherroub, and S. Szunerits, "Seed-mediated electrochemical growth of gold nanostructures on indium tin oxide thin films," Electrochimica Acta, vol. 53, no. 27, pp. 7838-7844, 2008.

[17] A. A. Umar, M. Oyama, M. M. Salleh, and B. Y. Majlis, "Formation of high-yield gold nanoplates on the surface: effective two-dimensional crystal growth of nanoseed in the presence of poly(vinylpyrrolidone) and cetyltrimethylammonium bromide," Crystal Growth and Design, vol. 9, no. 6, pp. 2835-2840, 2009.

[18] M. de la Garza, T. Hernández, R. Colás, and I. Gómez, “Deposition of gold nanoparticles on glass substrate by ultrasonic spray pyrolysis," Materials Science and Engineering B, vol. 174, no. 1-3, pp. 9-12, 2010.

[19] R. G. Palgrave and I. P. Parkin, "Aerosol assisted chemical vapor deposition of gold and nanocomposite thin films from hydrogen tetrachloroaurate(III)," Chemistry of Materials, vol. 19, no. 19, pp. 4639-4647, 2007.

[20] B. Ingham, T. H. Lim, C. J. Dotzler, A. Henning, M. F. Toney, and R. D. Tilley, "How nanoparticles coalesce: an in situ study of Au nanoparticle aggregation and grain growth," Chemistry of Materials, vol. 23, no. 14, pp. 3312-3317, 2011.

[21] D. Zhang, P. Diao, and Q. Zhang, "Potential-induced shape evolution of gold nanoparticles prepared on ITO substrate," Journal of Physical Chemistry C, vol.113, no. 36, pp. 15796-15800, 2009.

[22] B. Viswanath, P. Kundu, B. Mukherjee, and N. Ravishankar, "Predicting the growth of two-dimensional nanostructures," Nanotechnology, vol. 19, no. 19, Article ID 195603, 2008.

[23] Y. Hu, X. Diao, C. Wang, W. Hao, and T. Wang, "Effects of heat treatment on properties of ITO films prepared by $\mathrm{rf}$ magnetron sputtering," Vacuum, vol. 75, no. 2, pp. 183-188, 2004.

[24] J. Lee, D.-G. Lim, W. Song, and J. Yi, "Influence of annealing temperature and atmosphere on the properties of ITO films deposited using a powdery target," Journal of the Korean Physical Society, vol. 51, no. 3, pp. 1143-1146, 2007. 

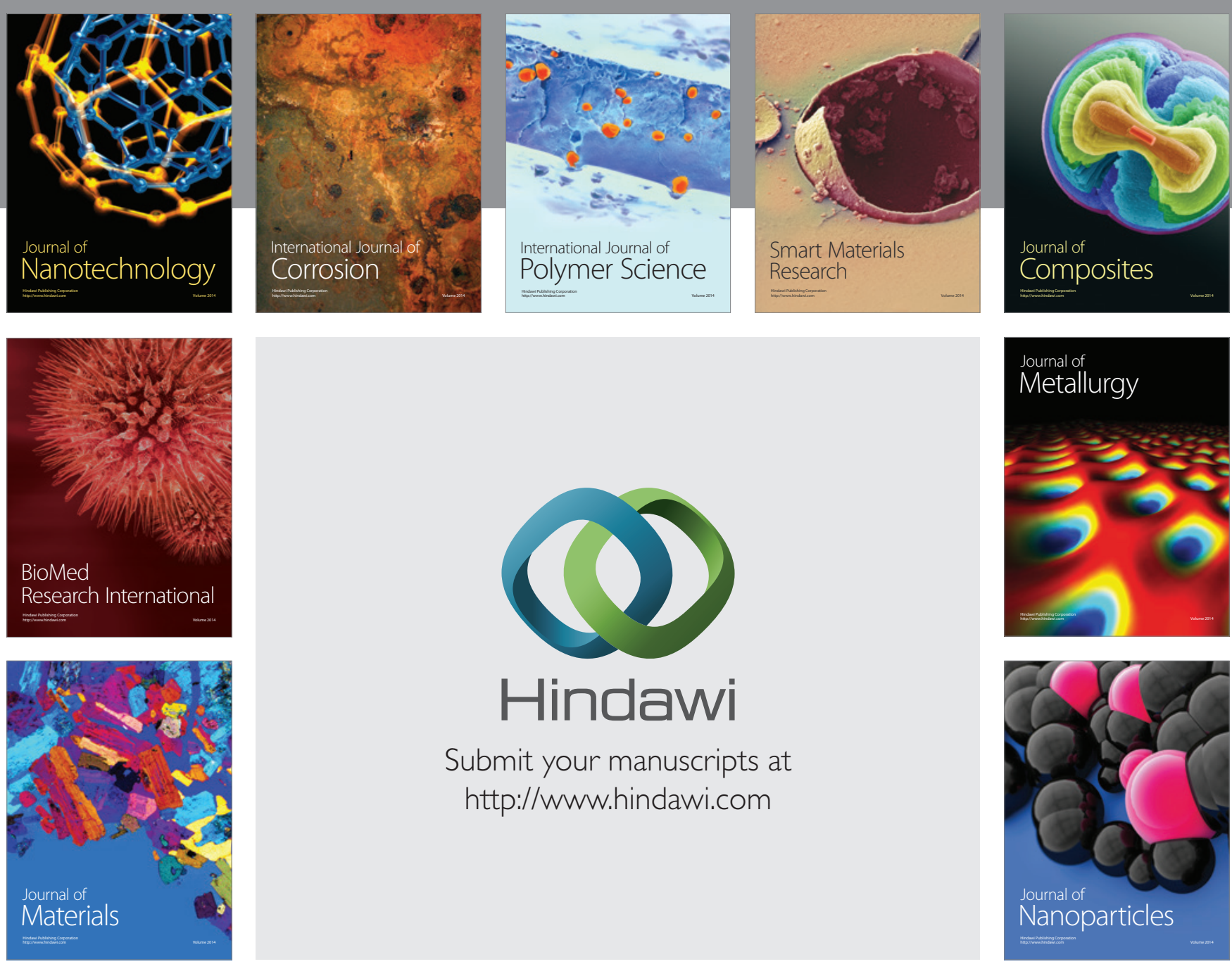

Submit your manuscripts at http://www.hindawi.com
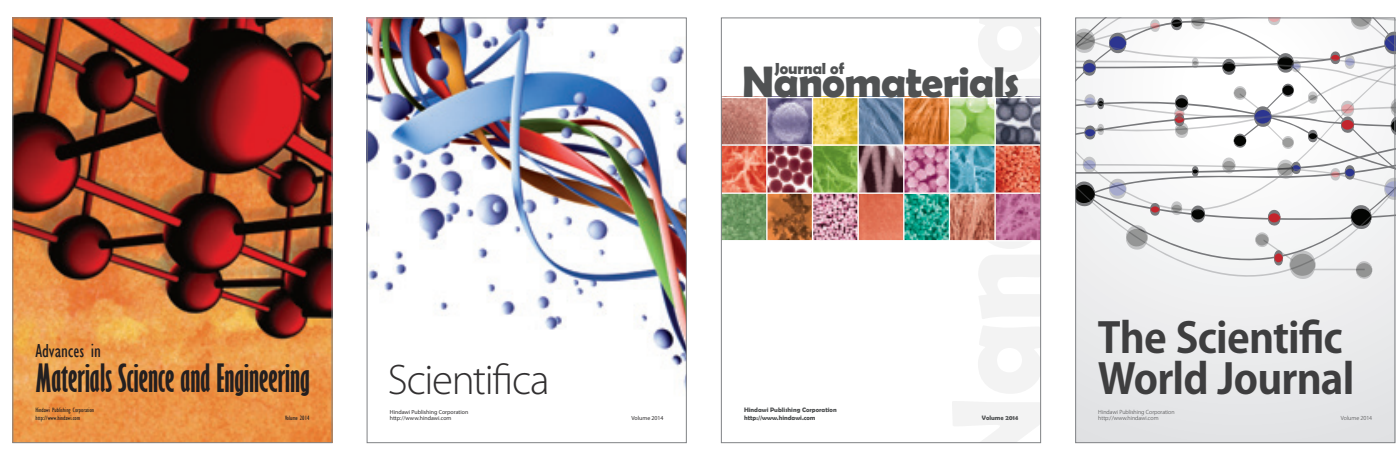

\section{The Scientific World Journal}
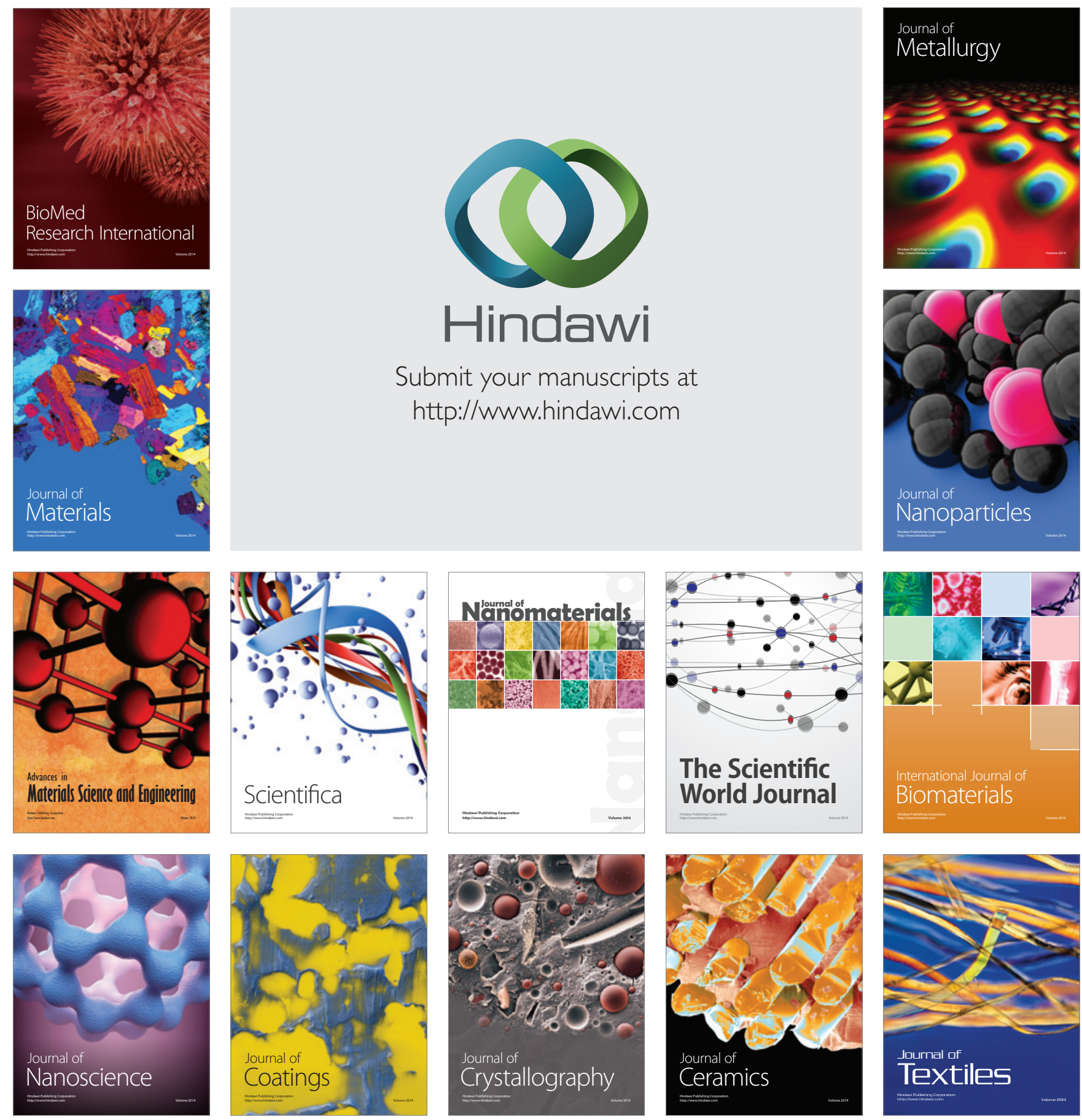